\title{
On the compatibility of Brewer total column ozone measurements in two adjacent valleys (Arosa and Davos) in the Swiss Alps
}

\author{
René Stübi $^{1}$, Herbert Schill ${ }^{2}$, Jörg Klausen ${ }^{1}$, Laurent Vuilleumier $^{1}$, Julian Gröbner ${ }^{3}$, Luca Egli ${ }^{3}$, and \\ Dominique Ruffieux ${ }^{1}$ \\ ${ }^{1}$ Federal Office of Meteorology and Climatology, MeteoSwiss, 1530 Payerne, Switzerland \\ ${ }^{2}$ Federal Office of Meteorology and Climatology, MeteoSwiss, Lichtklimatisches Observatorium, 7050 Arosa, Switzerland \\ ${ }^{3}$ Physikalisch-Meteorologisches Observatorium / World Radiation Center, 7260 Davos Dorf, Switzerland
}

Correspondence to: René Stübi (rene.stubi@meteoswiss.ch)

Received: 19 May 2017 - Discussion started: 3 July 2017

Revised: 26 September 2017 - Accepted: 3 October 2017 - Published: 21 November 2017

\begin{abstract}
The Arosa site is well known in the ozone community for its continuous total ozone column observations that have been recorded since 1926. Originally based on Dobson sun spectrophotometers, the site has been gradually complemented by three automatic Brewer instruments, in operation since 1998. To secure the long-term ozone monitoring in this Alpine region and to benefit from synergies with the World Radiation Center, the feasibility of moving this activity to the nearby site at Davos (aerial distance of $13 \mathrm{~km}$ ) has been explored. Concerns about a possible rupture of the 90 -yearlong record has motivated a careful comparison of the two sites, since great attention to the data continuity and quality has always been central to the operations of the observatory at Arosa. To this end, one element of the Arosa Brewer triad has been set up at the Davos site since November 2011 to realize a campaign of parallel measurements and to study the deviations between the three Brewer instruments. The analysis of the coincident measurement shows that the differences between Arosa and Davos remain within the range of the long-term stability of the Brewer instruments. A nonsignificant seasonal cycle is observed, which could possibly be induced by a stray-light bias and the altitude difference between the two sites. These differences are shown to be lower than the short-term variability of the time series and the overall uncertainty from individual Brewer instruments and therefore are not statistically significant. It is therefore concluded that the world's longest time series of the total ozone column obtained at Arosa site could be safely extended and continued with measurements taken from instruments located at the
\end{abstract}

nearby Davos site without introducing a bias to this unique record.

\section{Introduction}

Since the 1920s, high-quality ozone column measurements have been obtained by the sun spectrophotometry technique initially developed by Prof. G. Dobson (Basher, 1982; Komhyr et al., 1989). At that time, he created the first ozone network of the so-called Dobson instruments distributed at four sites in Europe, one of them being Arosa (Dobson, 1968). The high quality of the Arosa measurements was the result of a very involved scientist (Prof. W. P. Götz) carefully maintaining the observations in this high-altitude and low-pollution environment. This motivated Prof. G. Dobson to permanently leave an instrument for continuous operation at the LichtKlimatisches Observatorium (LKO) Arosa. The LKO had been founded a few years earlier at the initiative of a medical corporation with the initial purpose of understanding why Alpine atmosphere proved to be beneficial for patients suffering from tuberculosis disease (Staehelin et al., 2016). The long-term continuation of the ozone column monitoring at LKO has continued in the 1960s under the responsibility of Prof. H.-U. Dütsch and later on, from the 1980s, under the responsibility of Prof. J. Staehelin, associated with the Federal Office of Meteorology and Climatology (MeteoSwiss) to ensure the technical support and the development of the LKO. The Arosa ozone column measurement record is well known in the ozone community as the longest 
continuous series worldwide, starting in 1926 (Dütsch, 1984; Staehelin et al., 1998; Scarnato et al., 2009, 2010).

The ozone column time series was initially composed of measurements from a suite of manual and automatic Dobson sun spectrophotometers with various contiguous or overlapping operation periods as illustrated in the lower part of Fig. 1 (blue segments). On a regular basis since 1957, the ozone column series has been complemented by ozone profile measurements based on the Umkehr technique (Petropavlovskikh et al., 2009). From 1974 onwards, three Dobson instruments have been in operation at Arosa, with two instruments focused on ozone column and one on Umkehr profile measurements. In Fig. 1, the annual mean ozone column composite time series is illustrated. The depletion of stratospheric ozone, first observed in the polar regions (Solomon, 1999; Farman et al., 1985), has had a signature at midlatitudes of $\sim 5 \%$ decrease in the total ozone column, clearly evident in Arosa between 1970 and 1990 in Fig. 1 (blue broken lines). The effects of the Montreal protocol and its successive amendments appear as a leveling of the ozone column over the past decade (Pawson et al., 2014). This first stage of the ozone layer recovery is clear. However, the expected increase does not appear to be unambiguously and statistically significant in the LKO series.

Developed in Canada, the new generation Brewer sun spectrophotometers have been introduced to the market in the 1980s (Kerr et al., 1981; Kerr and McElroy, 1995). These fully automatic Brewer instruments have been gradually introduced at the LKO over the time period 1988 to 1998 to constitute a triad as illustrated at the top of Fig. 1 (red segments) (Stübi et al., 2017).

The Physikalisch-Meteorologisches Observatorium (PMOD) located in the adjacent Davos valley was founded in 1907 and played a similar role to the LKO. Today, PMOD is well known for its activities in the domain of radiation measurements and worldwide calibration services and has acquired the status of the World Radiation Center (WRC) for the World Meteorological Organization (WMO).

The question of pooling the PMOD/WRC and LKO resources has regularly been raised. This would result in a profit from synergies between the two institutions and improved efficiency. The main objection to a change of site for the ozone column monitoring has always been focused on the importance of the long LKO measurement series, which should be neither discontinued nor disrupted. To ensure the quality of these important historical Dobson and Brewer series in Switzerland in the long term, a new analysis of the situation was conducted at MeteoSwiss that led to a two-phase multiyear project.

In the first phase, the Dobson instruments were automated, resulting in a significant increase of the number of measurements as well as improved data quality. The description of the automated version of the Dobson instrument will be the subject of a separate publication. In parallel to these technical developments, a campaign of parallel Brewer measure-

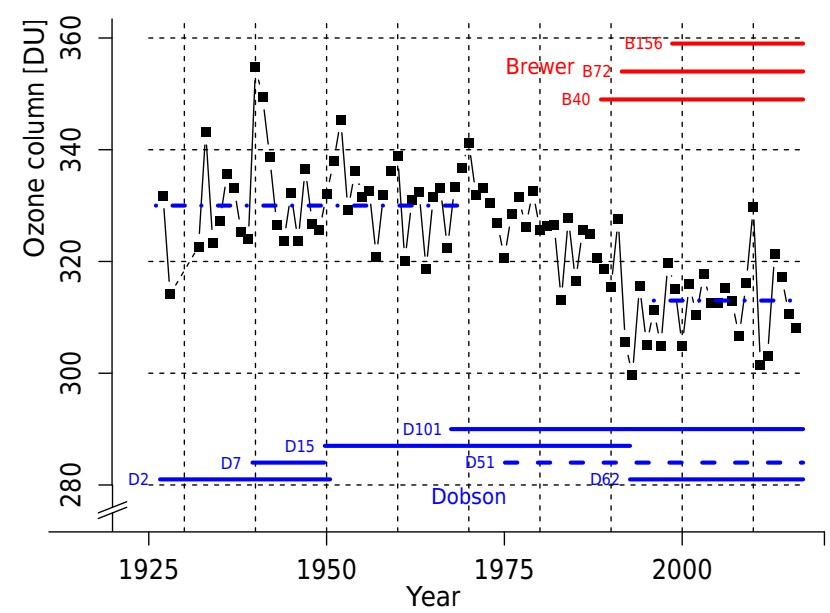

Figure 1. Time series of the annual mean ozone column above Arosa, Switzerland. The different instruments in operation are illustrated by blue segments for the Dobson and red segments for the Brewer instruments. Dobson $D_{051}$ is mostly dedicated to Umkehr measurements. The broken blue lines are the mean ozone column before 1970 and after 1997.

ments at the two sites Arosa and Davos was initiated to objectively determine the influences of the environment (e.g., altitude, surrounding topography) and location having a statistically significant effect on the measured ozone column. The results of this campaign are presented in this study. In the second phase, a similar campaign of parallel measurements with automated Dobson instruments has been running since January 2016. However, the middle-term stability and the calibration status after the major upgrade of these instruments have to be assessed before publishing these results and a 2-3-year comparison campaign is also necessary.

The 13 years of the Arosa Brewer triad covering the previous period 1998-2011 were carefully analyzed to quantify the reproducibility and the long-term stability of these Brewer measurements. The results of this latter analysis are described in Stübi et al. (2017) and reference to this publication will appear in the present analysis, since it is based on a similar approach. The combined information from the two studies provide objective scientific evidence on which to base a decision on relocating the Dobson and Brewer instruments from Arosa to Davos.

In Sect. 2, the two measurement sites are briefly presented with emphasis on the environmental factors with a potential to produce systematic effects. In Sect. 3, the instruments and the data sets are described, and the analysis of the 2010-2016 measurement period is presented with the Brewer $B_{072}$ instrument located first at Arosa (until the end of 2011) and then at Davos. The discussion of the results is found in Sect. 4, followed by the conclusions in Sect. 5 . 


\section{Sites characteristics}

Arosa is an alpine resort ( 2500 permanent inhabitants) in the Swiss Alps at a mean altitude of $1800 \mathrm{~m}$ a.s.l. surrounded by mountains with summits reaching $3000 \mathrm{~m}$ a.s.l. The LKO measurement site $\left(46.779^{\prime} \mathrm{N}, 9.675^{\prime} \mathrm{E}\right)$ is on the terrace of a building at $1850 \mathrm{ma}$ a.s.l., where the two triads of sun spectrophotometers (Dobson and Brewer) were collocated until the beginning of the campaign in November 2011. The area is isolated from major industrial pollution sources, since Arosa is connected to the Rhine valley by a $\sim 30 \mathrm{~km}$-long narrow valley and a altitude difference of $\sim 1000 \mathrm{~m}$ preventing the inflow of polluted air masses. There is an average of $\sim 300$ sunny days per year, allowing at least four direct sun observations with the most favorable clear-sky conditions in the morning hours.

Davos is a small city ( $\sim 12500$ permanent inhabitants) in the adjacent valley north-east of Arosa at a mean altitude of $1550 \mathrm{ma}$ a.s.l. The industrial activity is more developed at Davos than at Arosa but is still limited. The measurement site $(46.813 \mathrm{~N}, 9.844 \mathrm{E})$ is located in front of the PMOD/WRC building at $1590 \mathrm{~m}$. PMOD/WRC sits above a well-pronounced inversion layer, which effectively prevents local pollution from the valley reaching the observatory.

Figure 2 illustrates the horizon as seen from the LKO site (blue-shaded area) calculated from a model of the Swiss topography at $25 \mathrm{~m}$ horizontal resolution. The horizon seen from the PMOD/WRC site is illustrated by the red line. The blue lines correspond to the course of the sun at the beginning of each month from January to June. The two horizons present similarities with differences only at the extreme east and west for the summer months. However, this longer sun exposure of Arosa is not important as the observations are limited to air mass values $\mu \leq 4$ in order to reduce the effect of the stray-light interference in the single-monochromator Brewer instruments (see next section).

At the bottom of Fig. 2, the six black lines correspond to the daily cycle of the $\mu$ values for the illustrated sun courses and the horizontal line to the limit $\mu=4$. The extra sun duration time for the Arosa site and $\mu$ values below this limit only occur during the late afternoon hours in summer. However, in the alpine environment clouds are frequently present at that time of the day and the presence of trees in the northwest direction of the LKO site prevents measurements until the sun reaches the horizon. Similarly to Arosa, the number of days appropriate for direct sun measurements at Davos is $\sim 300$ per year. Finally, the horizontal distance between Arosa and Davos sites is $\sim 13 \mathrm{~km}$ and the altitude difference is $\sim 260 \mathrm{~m}$.

In summary, the basic characteristics of the sites can be considered to be very similar, which should, a priori, limit the site-specific differences in the ozone column.

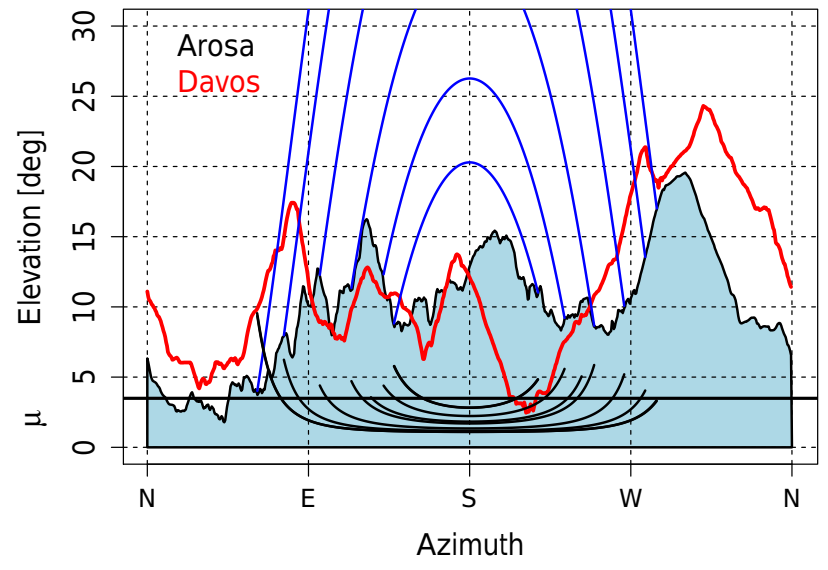

Figure 2. Calculated horizon from the Arosa (blue shaded) and Davos (red line) sites. The blue lines refer to the course of the sun at the beginning of the month from January to June. The black lines are the corresponding air mass $\mu$ daily cycle for the different sun elevation curves.

\section{Instruments and analysis}

For the comparison of the Arosa and Davos sites, the Mark II single-monochromator Brewer $B_{072}$ from the Arosa triad was moved to Davos and parallel measurements started on 22 November 2011. Besides a 5-week interruption at the beginning of 2013 (1 February 2013-4 March 2013) due to technical problems, the operation has continued as intended.

Three maintenance/calibration campaigns with the European Brewer Calibration Center (RBCC-E) traveling reference instrument have taken place during that period to ensure the good working conditions of the different instruments. The first one happened in July 2012 and the second in July 2014 at LKO. Brewer $B_{072}$ was transported back to Arosa for this purpose for a short period in 2012 and a longer one in 2014 (see illustration in Fig. 3). In the third campaign in 2016, the instrument $B_{072}$ was calibrated in Davos and the instruments $B_{040}$ and $B_{156}$ were subsequently calibrated in Arosa. To get a long-term perspective of the changes of the instruments' extraterrestrial constant (ETC) and the ozone absorption coefficient, we refer to Fig. 2 of Stübi et al. (2017). In Table 1, the recent changes of these parameters are reported. It can be seen that, besides the change of the ETC for Brewer $B_{072}$ in 2014, only minor corrections have been necessary to keep the instruments in agreement with the traveling reference instrument (Redondas et al., 2015; Redondas and Rodriquez-Franco, 2015). The change of $B_{072}$ ETC resulted from the improvement of the UV focusing, which significantly changed the response of the instrument (Redondas and Rodriquez-Franco, 2015). The other changes are related to the update of the temperature coefficients (in 2014 for $B_{156}$ and in 2016 for $B_{040}$ ) and the dead time (in 2012 for $B_{040}$, in 2014 for $B_{072}$ and in 2016 for $B_{156}$ ). 
Table 1. ETC and ozone absorption coefficient of the Arosa triad Brewer instruments from the last three calibration campaigns.

\begin{tabular}{lrrrr}
\hline Parameter & Validity period & $B_{040}$ & $B_{072}$ & $B_{156}$ \\
\hline ETC & $2010-2012$ & 2985 & 3168 & 1750 \\
& $2012-2014$ & 2980 & 3180 & 1765 \\
& $2014-2016$ & 2970 & 3223 & 1750 \\
& $2016-$ & 2950 & 3215 & 1740 \\
\hline $\mathrm{O}_{3}$ & $2010-2012$ & 0.3335 & 0.3397 & 0.3326 \\
absorption & $2012-2014$ & 0.3335 & 0.3386 & 0.3402 \\
coefficient & $2014-2016$ & 0.3335 & 0.3377 & 0.3390 \\
& $2016-$ & 0.3357 & 0.3377 & 0.3405 \\
\hline
\end{tabular}

Details on the Arosa Brewer instruments are given in Stübi et al. (2017), therefore only a summary is presented here. The instruments were operated according to the standard acquisition and processing programs. The instrument constants were adjusted during the calibration campaigns and in between them, the data were reprocessed according to the time series of the internal lamps tests results. Only the direct sun observations were considered in this analysis and they were subject to an automatic and visual data screening on a daily basis, taking advantage of the presence of multiple collocated instruments at LKO, of ancillary surface radiation measurements and of cloud observations. Individual direct sun observations for each Brewer instrument has to satisfy the standard deviation (SD) criteria $\left(\sigma_{\mathrm{O}_{3}} \leq 2.5 \mathrm{DU}\right)$ and only data with air mass factor $\mu \leq 4.0$ were used in the present analysis.

For the comparison of Brewer total ozone data, coincident criteria were defined as time difference $\delta t \leq 5 \mathrm{~min}$ and air mass difference $\delta \mu \leq 0.05$. Since the measurement program of all three Brewer instruments was driven by the same set of commands according to the solar zenith angle (SZA), $90 \%$ of the coincidences were within $\delta t \sim \pm 100$ s and $\delta \mu \sim \pm 0.016$.

Figure 3 presents the differences of the coincident measurements of the Brewer instruments $B_{040}$ and $B_{072}$ over the time period 2010-2016 in Dobson units (blue) and reported to the midday ozone column in [\%] (red). This figure does not allow any substantial break to be distinguished in the series resulting from the transfer of the Brewer $B_{072}$ instrument to Davos. During the time period 2010-2012 when the three instruments were collocated at Arosa, only a limited number of differences exceeded $\pm 5 \mathrm{DU}$, while this number increased when the instruments were apart. A slight seasonal cycle can also be noticed in this figure.

The parameters of the distribution of the differences series are given in Table 2. The total number of coincident measurements were of the order of $\sim 50000$, about half for collocation and half for distant locations as shown in the last column of Table 2 . The medians of the distributions showed a shift of the order of $0.25 \%$ when Brewer $B_{072}$ was located at Davos accompanied by a widening of the interquantiles $Q_{75 \%}-Q_{25 \%}\left(Q_{97.5 \%}-Q_{2.5 \%}\right)$ of $0.2 \%(0.8 \%)$. The

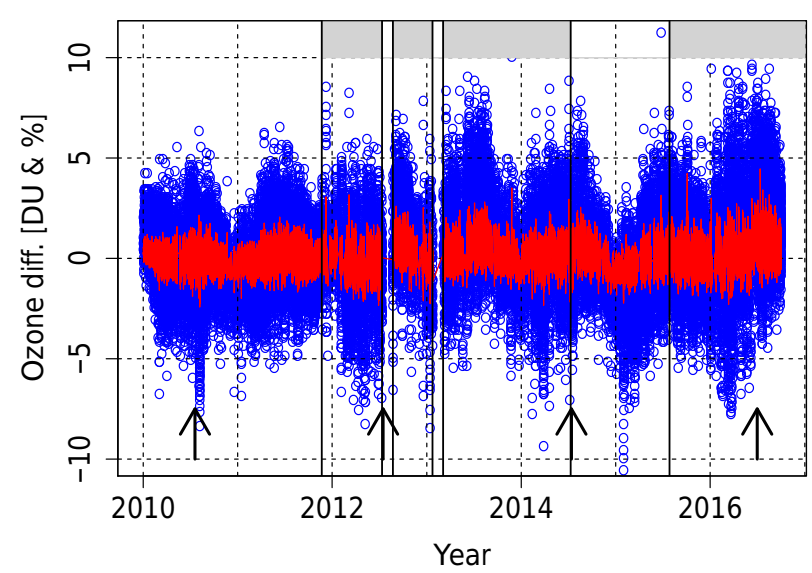

Figure 3. Time series of the differences between coincident measurements of the Brewer instruments $B_{040}$ and $B_{072}$ over the period 2010-2016. Blue: difference in DU units. Red: difference in [\%]. The arrows indicate the calibration campaigns and the gray-shaded areas denote the periods when Brewer instrument $B_{072}$ was operating in Davos.

differences between two Mark II and between a Mark II and a Mark III was $\sim 0.2 \%$, which could be a sign of a stray-light effect if these features present a seasonal component. The overall changes reported in Table 2 correspond to differences of the order of one Dobson unit. To reveal such small differences, the instruments must be very well maintained and calibrated, as they were during the campaigns.

In order to gain a clearer picture of the temporal evolution of the coincident data, the time series were aggregated to monthly median values. The resulting difference time series for the three pairs of Brewer instruments are shown in Fig. 4 together with the $2 \sigma$ error bars. The monthly median differences between the collocated $B_{040}$ and $B_{156}$ instruments (middle panel) were mostly within the $\pm 0.5 \%$ limits. On the lower and upper panels, the median variations were larger, touching or crossing the $\pm 0.5 \%$ limits more frequently and exhibiting larger variability.

To further characterize the data presented above, the time series were decomposed into a systematic and a random component on a daily basis following the method in Stübi et al. (2017). The first term is a measure of the long-term stability, while the second term is linked to the short-term variability. The pair of collocated Brewer instruments at LKO $\left(B_{040}\right.$ and $B_{156}$ ) were considered as the reference. The diurnal variation of the ozone column was modeled as a fourth-order polynomial function of the time difference with 12:00 UTC fitted on all the measurements of the two reference Brewer instruments and satisfying the quality and coincident criteria. A further constraint to avoid outliers and spurious coincidences was the requirement to have at least five coincident measurements for each Brewer instrument in the course of the day. Each Brewer instrument was then characterized by 
Table 2. Quantiles of the distributions of the differences expressed in [\%] between pairs of Brewer instruments collocated at Arosa (period LKO) or with $B_{072}$ at PMOD/WRC (period PMOD).

\begin{tabular}{llrrrrrrrr}
\hline Brewer pair & Period & $Q_{2.5 \%}$ & $Q_{25 \%}$ & Median & $Q_{75 \%}$ & $Q_{97.5 \%}$ & $Q_{75 \%}-Q_{25 \%}$ & $Q_{97.5 \%}-Q_{2.5 \%}$ & Sample \\
\hline$\left(B_{072}-B_{040}\right) / B_{040}$ & LKO & -0.98 & -0.37 & -0.03 & 0.29 & 0.99 & 0.66 & 1.97 & 28191 \\
& PMOD & -1.07 & -0.19 & 0.23 & 0.68 & 1.68 & 0.87 & 2.75 & 25752 \\
\hline$\left(B_{156}-B_{040}\right) / B_{040}$ & LKO & -1.30 & -0.45 & -0.03 & 0.38 & 1.21 & 0.83 & 2.51 & 25643 \\
& PMOD & -1.18 & -0.33 & 0.12 & 0.56 & 1.47 & 0.89 & 2.65 & 25647 \\
& whole & -1.24 & -0.39 & 0.04 & 0.47 & 1.38 & 0.86 & 2.62 & 51290 \\
\hline$\left(B_{072}-B_{156}\right) / B_{156}$ & LKO & -1.40 & -0.50 & -0.09 & 0.34 & 1.28 & 0.84 & 2.68 & 20706 \\
& PMOD & -1.58 & -0.38 & 0.16 & 0.70 & 1.87 & 1.07 & 3.45 & 21153 \\
\hline
\end{tabular}
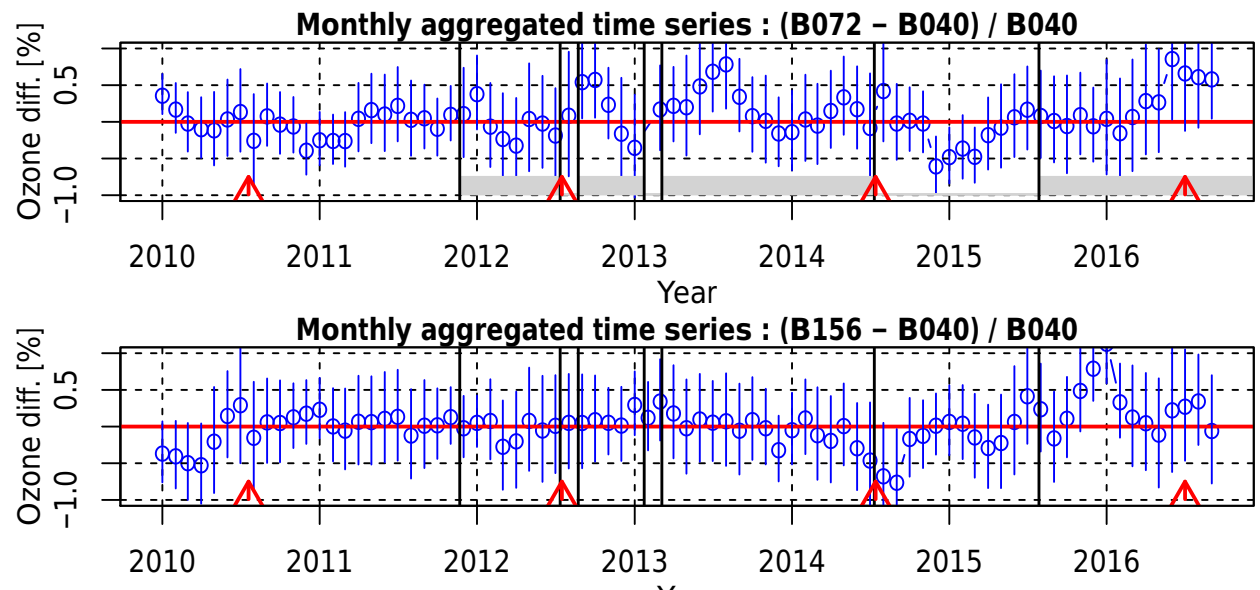

Year

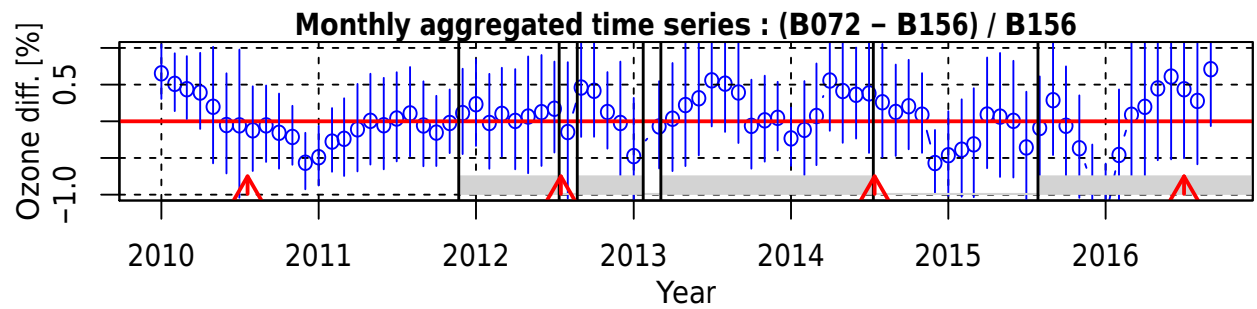

Figure 4. Time series of the monthly median differences of coincident ozone column measurements by pairs of Brewer instruments. The gray zones underline the periods when the Brewer $B_{072}$ instrument was located at Davos. The blue bars correspond to 1 SD.

an offset $\delta_{B_{\mathrm{nnn}}}$ and a SD $\sigma_{B_{\mathrm{nnn}}}$ calculated as:

$\delta_{B_{\mathrm{nnn}}}=\operatorname{median}\left(\sum_{i=1}^{n}\left[\left\{\mathrm{O}_{3_{B_{\mathrm{nnn}}}}\right\}_{i}-\left\{\mathrm{O}_{3_{\mathrm{poly}}}\right\}_{i}\right]\right)$

$\sigma_{B_{\mathrm{nnn}}}=\sqrt{\begin{array}{l}\sum_{i=1}^{n}\left(\left[\left\{\mathrm{O}_{3_{B_{\mathrm{nnn}}}}\right\}_{i}-\left\{\mathrm{O}_{3_{\text {poly }}}\right\}_{i}\right]\right. \\ \left.-E\left[\left\{\mathrm{O}_{3_{B_{\mathrm{nnn}}}}\right\}_{i}-\left\{\mathrm{O}_{3_{\text {poly }}}\right\}_{i}\right]\right)^{2} /(n-1)\end{array}}$

$\left\{\mathrm{O}_{3_{B n n}}\right\}_{i}$ being the measured data, $\left\{\mathrm{O}_{3_{\text {poly }}}\right\}_{i}$ being the model data and $E[x]$ the mean value operator. As the ozone column varies smoothly on the timescale of a few hours, the value interpolated at noon was considered the ozone column representative for that day.
The offset $\delta_{B_{\text {nnn }}}$ represented the shift of the polynomial function to fit each instrument separately. The $\mathrm{SD} \sigma_{B_{\mathrm{nnn}}}$ was a measure of the dispersion of the data around the smoothed daily variation represented by the polynomial function.

The fourth order polynomial as a model for the diurnal variation is not critical and alternative fit functions did not affect the results.

Figure 5 illustrates the procedure with the mean diurnal variation from the two reference instruments (black line) and the three individually fitted lines (broken lines) displaced for this particular day by the offsets: $\delta_{B_{040}}=-0.33 \mathrm{DU}$, $\delta_{B_{072}}=0.65 \mathrm{DU}$ and $\delta_{B_{156}}=0.45 \mathrm{DU}$. The SDs for the three Brewer instruments amounted to $\sigma_{B_{040}}=1.2, \sigma_{B_{072}}=1.1$ and $\sigma_{B_{156}}=1.1 \mathrm{DU}$. 


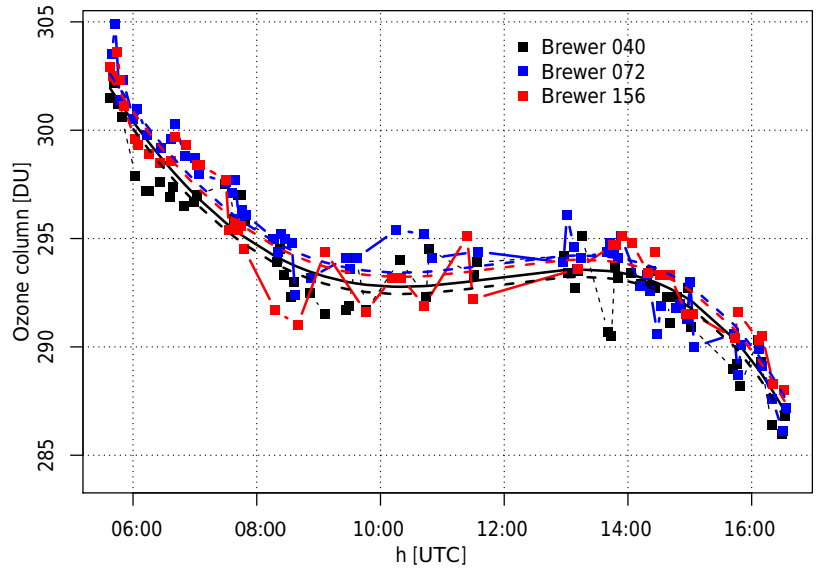

Figure 5. Diurnal variability of the Brewer triad for 12 July 2011: ozone column vs. time [UTC]. The continuous black line is the model diurnal variation and the dashed lines correspond to the model adjusted to each Brewer data set. The black, blue and red colors correspond to the $B_{040}, B_{072}$ and $B_{156}$ Brewer instruments.

The time series of the monthly median of $\delta$ and $\sigma$ terms divided by the ozone column at noon [\%] for the three Brewer instruments are illustrated in Fig. 6 for the period 2010-2016. The $\delta$ variations for $B_{040}$ and $B_{156}$ instruments mirror each other, since they constituted the reference for the diurnal variation. They were below $\pm 0.3 \%$ for the entire period except at the end of 2015-beginning of 2016. The interquantile ranges $Q_{97.5 \%}-Q_{2.5 \%}$ were only occasionally larger than $0.5 \%$ for these two instruments (error bars on Fig. 6). The time series $\delta_{B_{072}}$ exhibited larger variations with extremes reaching $\pm 0.7 \%$ for the median. Similarly, the error bars for $B_{072}$ were larger as expected, since this instrument is not part of the reference. These deviations of the $\delta_{B_{072}}$ series presented a structured pattern which required further attention.

For the $\sigma$ time series, the differences were much less pronounced, reflecting the fact that $\sigma$ was an intrinsic factor of each instrument. The range of $\sigma$ for the $B_{040}$ and $B_{156}$ instruments was between $\sim 0.2 \%$ and $\sim 0.5 \%$, while for $B_{072}$, it was slightly larger by $\sim 0.1 \%$ but not significantly, considering the $Q_{97.5 \%}-Q_{2.5} \%$ interquantile ranges. A distinct annual modulation in these $\sigma$ series was present for the three instruments.

In Table 3, the parameters of the distributions of the $\delta$ series are reported in the upper part and the parameters of the $\sigma$ series in the lower part. The $\delta$ series medians for the reference instruments were very close to zero, while a shift of the $\delta_{B_{072}}$ distribution of $\sim 0.2 \%$ appeared when the instrument was located at Davos. The interquantile $Q_{97.5 \%}-Q_{2.5} \%$ range of this last distribution was twice larger than the other single-monochromator $B_{040}$ when the $B_{072}$ instrument was collocated at Arosa and it widened to three times when it was located at Davos. While the two time periods should be indis- tinguishable for the $B_{040}$ and $B_{156}$ instruments, a variability of $\pm 0.1-0.2 \%$ of the different quantiles was observed.

The three $\sigma$ distribution parameters of the Brewer triad were very consistent with each other as seen in the lower part of Table 3. The two reference Brewer instruments $\left(B_{040}\right.$ and $B_{156}$ ) exhibited a similar median of $\sim 0.35 \%$. The interquantile range $Q_{97.5 \%}-Q_{2.5} \%$ was $\sim 0.85 \%$ for the reference instruments. For the Brewer $B_{072}$ instrument, the median was $\sim 0.40 \%$ and the interquantile range $Q_{97.5 \%-}$ $Q_{2.5} \%$ was respectively 0.96 and $1.06 \%$ for the LKO and the PMOD/WRC periods.

The stray light refers to the interfering radiation source out of the desired band measured by a specific instrument. The origin could be either internal to the instrument due to multiple reflections or external from the scattered light in the atmosphere entering the field of view of the instrument. Stray light predominantly affects the measurements of the shortest wavelengths of the Brewer and Dobson instruments at large ozone slant columns $(\mathrm{SC}=$ ozone column $\times$ air mass $=\mathrm{O}_{3} \times \mu$ ), which produces a low bias of the measured ozone column (Scarnato et al., 2009; Petropavlovskikh et al., 2011; Christodoulakis et al., 2015). This effect particularly concerns Dobson and single-monochromator Brewer instruments located at high latitude and it varies from instrument to instrument (Karppinen et al., 2015). To reduce these interferences in this study, the observations were limited to air mass values $\mu \leq 4$, which corresponds to a SC of $\sim 1200 \mathrm{DU}$ for the typical $\sim 300 \mathrm{DU}$ ozone column of Arosa. To further analyze the stray-light potential influence, the seasonality of the SC distribution averaged over the period 2011-2017 was calculated as illustrated in Fig. 7. From April to October the SC was below 800 for $90 \%$ of the data, which were essentially free of the stray-light effect as is the case for most of the Brewer instruments. Contrarily, measurements in December and January showed SC values above 800 which may potentially have induced a low ozone column bias for the two single-monochromator instruments, $B_{040}$ and $B_{072}$. To evaluate the importance of this effect on the results of the present analysis, the $\delta$ time series was grouped into three classes of SC according to the median of the monthly SC distributions illustrated in Fig. 7 by the red lines. Figure 8 shows the results as box plots. In the upper panel corresponding to the Arosa period with three collocated instruments, only Brewer $B_{072}$ showed a significant SC dependence. Brewer $B_{040}$ had a better stray-light rejection and presented no SC dependence. In the lower panel corresponding to the Davos period, the three $B_{072}$ box plots showed a similar SC-induced pattern but slightly shifted upwards. $\mathrm{A} \sim-0.2 \mathrm{DU}$ low ozone bias was therefore expected for $B_{072}$ during the period November to February.

The seasonal variation can be better analyzed on aggregated $\delta$ time series in monthly medians as illustrated in Fig. 9. The upper panel is for the months with the three Brewer instruments collocated at Arosa and the lower panel for the Davos period. The errors bars are the interquantile ranges 
Table 3. Quantiles of the distribution of the parameters $\delta$ and $\sigma$ of the three Brewer instruments expressed in [\%]. Under the "period" column, LKO means that the $B_{072}$ instrument was collocated at Arosa, PMOD corresponds to having $B_{072}$ at Davos and "all" is for the whole period. The sample sizes were 705 days for the Arosa period and 801 days for the Davos period.

\begin{tabular}{llrrrrrrr}
\hline Parameter & Period & $Q_{2.5 \%}$ & $Q_{25} \%$ & Median & $Q_{75 \%}$ & $Q_{97.5 \%}$ & $Q_{75 \%}-Q_{25} \%$ & $Q_{97.5 \%}-Q_{2.5 \%}$ \\
\hline$\delta B_{040}$ & LKO & -0.31 & -0.09 & 0.01 & 0.10 & 0.35 & 0.19 & 0.66 \\
& PMOD & -0.50 & -0.16 & -0.04 & 0.06 & 0.26 & 0.22 & 0.76 \\
\hline$\delta B_{156}$ & LKO & -0.41 & -0.13 & -0.02 & 0.11 & 0.32 & 0.26 & 0.73 \\
& PMOD & -0.33 & -0.08 & 0.04 & 0.18 & 0.55 & 0.26 & 0.88 \\
\hline$\delta B_{072}$ & LKO & -0.70 & -0.20 & 0.03 & 0.21 & 0.66 & 0.41 & 1.36 \\
& PMOD & -0.77 & -0.09 & 0.21 & 0.52 & 1.07 & 0.61 & 1.84 \\
\hline$\sigma B_{040}$ & All & 0.17 & 0.28 & 0.34 & 0.41 & 0.57 & 0.69 & 0.84 \\
\hline$\sigma B_{156}$ & All & 0.18 & 0.30 & 0.37 & 0.45 & 0.61 & 0.75 & 0.89 \\
\hline$\sigma B_{072}$ & LKO & 0.19 & 0.31 & 0.39 & 0.48 & 0.77 & 0.79 & 0.96 \\
& PMOD & 0.21 & 0.35 & 0.44 & 0.55 & 0.85 & 0.90 & 1.06 \\
\hline
\end{tabular}
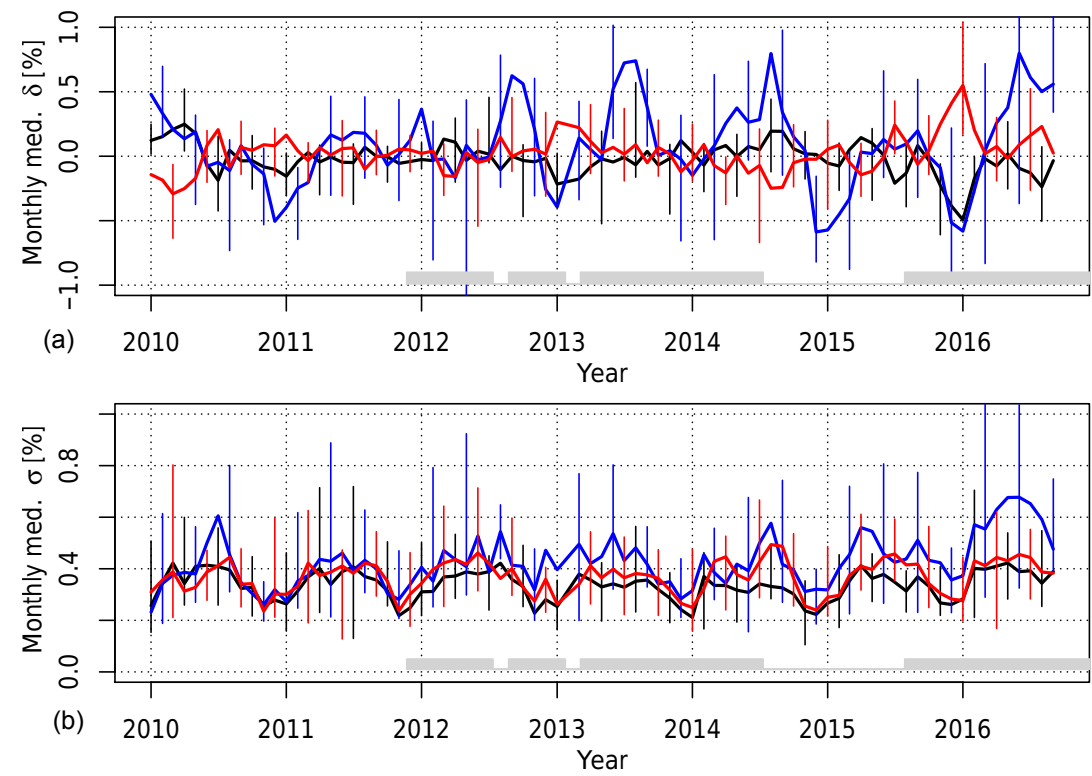

Figure 6. Time series of the monthly median offset $\delta$ (upper panel) and median SDs $\sigma$ (lower panel) over the time period 2010-2016. The black, blue and red lines correspond to Brewer $B_{040}, B_{072}$ and $B_{156}$ instruments. The error bars corresponding to the interquantiles $Q_{97.5 \%}-Q_{2.5} \%$ ranges are displayed every third month for clarity. The gray areas show the time periods when the Brewer $B_{072}$ instrument was located at Davos

$Q_{97.5 \%}-Q_{2.5 \%}$. No seasonal cycle can be distinguished on the $\delta_{B_{040}}$ and $\delta_{B_{156}}$ monthly median series on the upper panel nor on the lower panel. The Brewer $B_{072}$ aggregated $\delta_{B_{072}}$ series present a discernible seasonal component at both locations even if it is not significant at the $95 \%$ level except for December of the Arosa period. The expected low ozone bias for the Brewer $B_{072}$ discussed above appears in Fig. 9 when the $\mathrm{SC}$ is large in the November to March period.

The altitude difference between Arosa and Davos of $260 \mathrm{~m}$ introduces a difference in total column ozone above the two sites. Unfortunately, without actual measurements, it is im- possible to characterize the ozone column above Davos from the surface to $260 \mathrm{~m}$ above the ground, but surface ozone observations at the two locations and a comparison with freetropospheric observations can be used to derive meaningful boundaries on the magnitude of this difference. At Arosa, surface ozone observations are conducted by the local authorities at the LKO site. At Davos, a surface ozone station is operated as part of the Federal air pollution monitoring network (NABEL). This station is $900 \mathrm{~m}$ away from the PMOD/WRC site on a $35 \mathrm{~m}$-high tower in a forest. As discussed by Chevalier et al. (2007) for the central European 


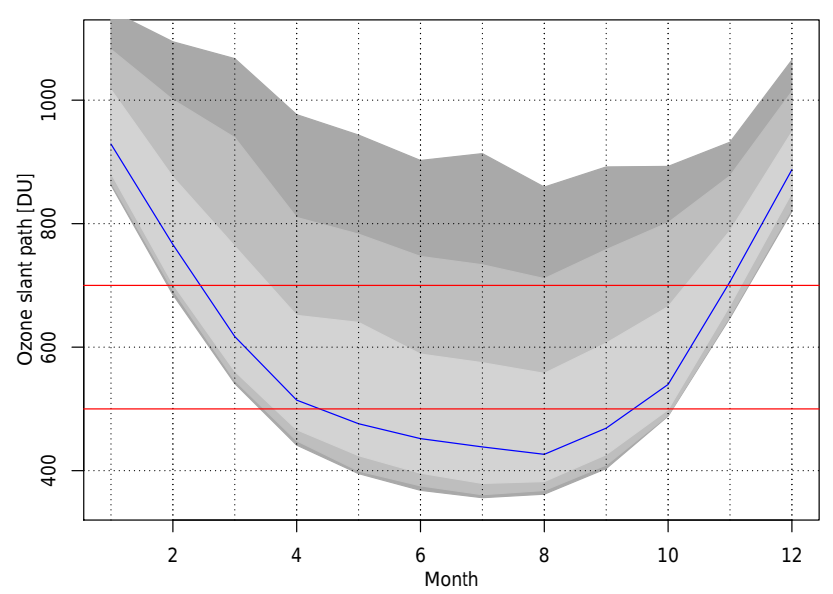

Figure 7. Seasonal cycle of the slant column over Arosa. The different bands from dark gray to light gray encompass the respective SC limits of $Q_{97.5 \%}-Q_{2.5} \%, Q_{90 \%}-Q_{10 \%}$ and $Q_{75 \%}-Q_{25} \%$. The blue line is for the monthly medians.

region, ozone concentrations in the free troposphere increase with altitude fairly consistently, irrespective of geographical location. However, this stratification can be modulated substantially by surface effects. Thus, surface ozone observations made at stations below $1200 \mathrm{ma}$ a.s.l. were found to be as much as $40 \%$ lower than those observed by aircraft and ozone balloon sondes in the free troposphere. The deviations decreased with increasing altitude of the stations to less than $8 \%$ for stations above $2000 \mathrm{~m}$ a.s.l. The mean annual surface ozone concentrations observed at Arosa (42.3 $\pm 8.2 \mathrm{ppb})$ and Davos $(42.0 \pm 7.1)$ were found to be very similar despite the difference in altitude (see Fig. 4 in Chevalier et al., 2007). Both stations exhibit about $5 \mathrm{ppb}$ lower ozone concentrations than expected from free-tropospheric profiles, with hourly variabilities of $\sim 11 \mathrm{ppb}$ in summer and $\sim 8 \mathrm{ppb}$ in winter. The seasonal variability was of the order of $15-20 \mathrm{ppb}$. This variability is likely due to changing weather and synopticscale transport, with superimposed photochemical effects of local pollution.

Under the hypothesis of a constant ozone mixing ratio above the inversion layer mentioned in Sect. 2, the partial ozone column can be estimated as

$$
\begin{aligned}
& \Delta \text { Column } \mathrm{O}_{3}(t)=\int_{p_{\text {Davos }}(t)}^{p_{\text {Arosa }}(t)} \mathrm{O}_{3}(t, p) \times \mathrm{d} \ln p \\
& =0.79 \times\left\{\ln \left(p_{\text {Davos }}(t)\right)-\ln \left(p_{\text {Arosa }}(t)\right)\right\} \times \mathrm{O}_{3}(t)[\mathrm{DU}],
\end{aligned}
$$

with the ozone $\mathrm{O}_{3}(t)$ [ppm] values measured at Davos NABEL surface station. The result of this simple calculation based on the hourly daytime measurements over the time period 2006-2014 is shown in Fig. 10 and suggests an average contribution of the partial ozone column to the total ozone column above Davos of $\sim 0.25 \pm 0.15 \%$.

\section{Discussion}

The Brewer sun spectrophotometers are very reliable instruments which allow the measuring of the ozone column in a fully automated mode within $1 \%$ reproducibility. It is therefore well adapted to compare two different sites under the same measurement program. This allowed us to generate a large data set of coincident measurements to evaluate the potential impact of the instrument location on the measurements during an extended period of time. This approach is in line with the Global Climate Observing System (GCOS) monitoring principles 1 and 2 (GCOS, 2003), which states that an assessment of impact should be made before the implementation of a change and a suitable period of overlap of the observing systems is required. These GCOS principles have been applied here to document a possible move of the Arosa-based ozone column monitoring activities at the nearby Davos site

The traceability of the Arosa Brewer instruments with respect to the global network is ensured by the regular maintenance and calibration campaigns which have demonstrated an agreement with the RBCC-E traveling reference to within $\pm 1 \%$ and even closer to within $\pm 0.5 \%$ in recent years. The present analysis concentrated on the study of the relative difference between the measurements obtained from the traveling Brewer instrument $B_{072}$ located either at Arosa or at Davos and the two other instruments of the Arosa Brewer triad ( $B_{040}$ and $\left.B_{156}\right)$.

The large number of direct coincident measurements reported in Table 2 and illustrated in Fig. 3 showed that no significant differences were present at this stage. It was not possible to identify minor influences of the sites and a further step in the analysis was required. It consisted of a separation of two terms: the short-term variability $\sigma$ (random term) and the longer-term stability $\delta$ (systematic term). The same approach was already used in Stübi et al. (2017) to evaluate the quality of the Arosa Brewer triad measurements. According to the conclusions of this previous study, the Arosa Brewer instruments present a stability of $\sim 0.40 \%$ over a timescale of a decade and a short-term variability of $\sim 0.3 \%$, in good agreement with a similar analysis of the world reference Brewer triad at Toronto (Fioletov et al., 2005; Kerr and al., 1998).

The results of this method are presented in Table 3 and Fig. 6 . The three $\sigma$ distributions present a seasonal variation of $\sim 0.2 \%$. The larger air mass factors prevailing in winter induced a larger difference between the measurement signals and the extraterrestrial constant and potentially a better signal-to-noise ratio, thus reducing $\sigma$. In summer, in particular, the sun radiation intensity at the ground level changes by many orders of magnitude and therefore neutral density filters are used in the Brewer instrument to attenuate the signal by known factors to avoid the saturation of the photomultiplier. The transitions between the different neutral density filters may be a source of additional fluctuations enhancing 

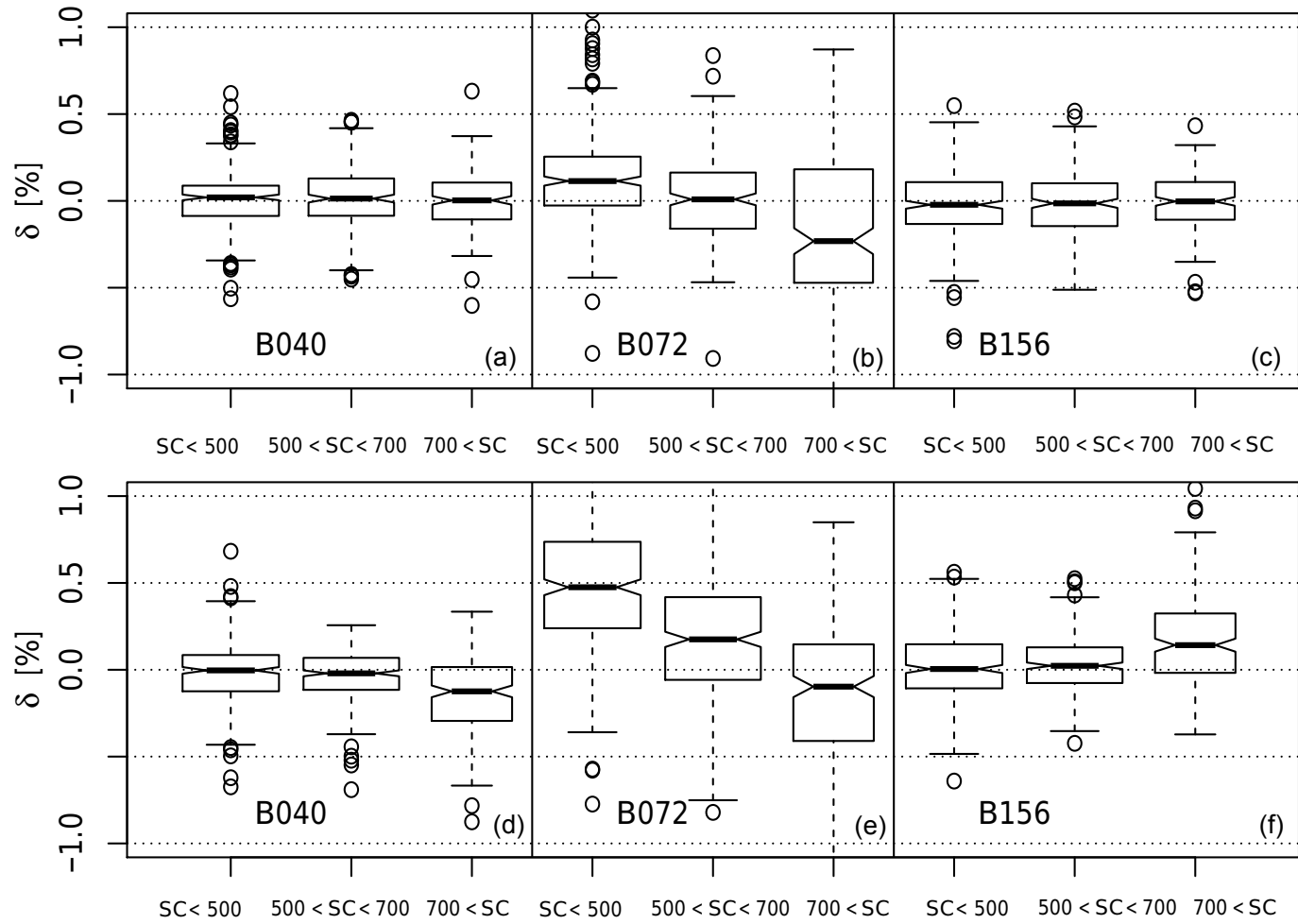

Figure 8. Box plot of the $\delta$ time series of the three Brewer instruments according to three classes for the median of the ozone slant column monthly distributions (red lines in Fig. 7): median SC $\leq 500,500<$ median SC $\leq 700$ and $700<$ median SC. The upper panel is for the Arosa period, the lower panel for the Davos period and from left to right, the distributions of $\delta_{B_{040}}, \delta_{B_{072}}$ and $\delta_{B_{156}}$.
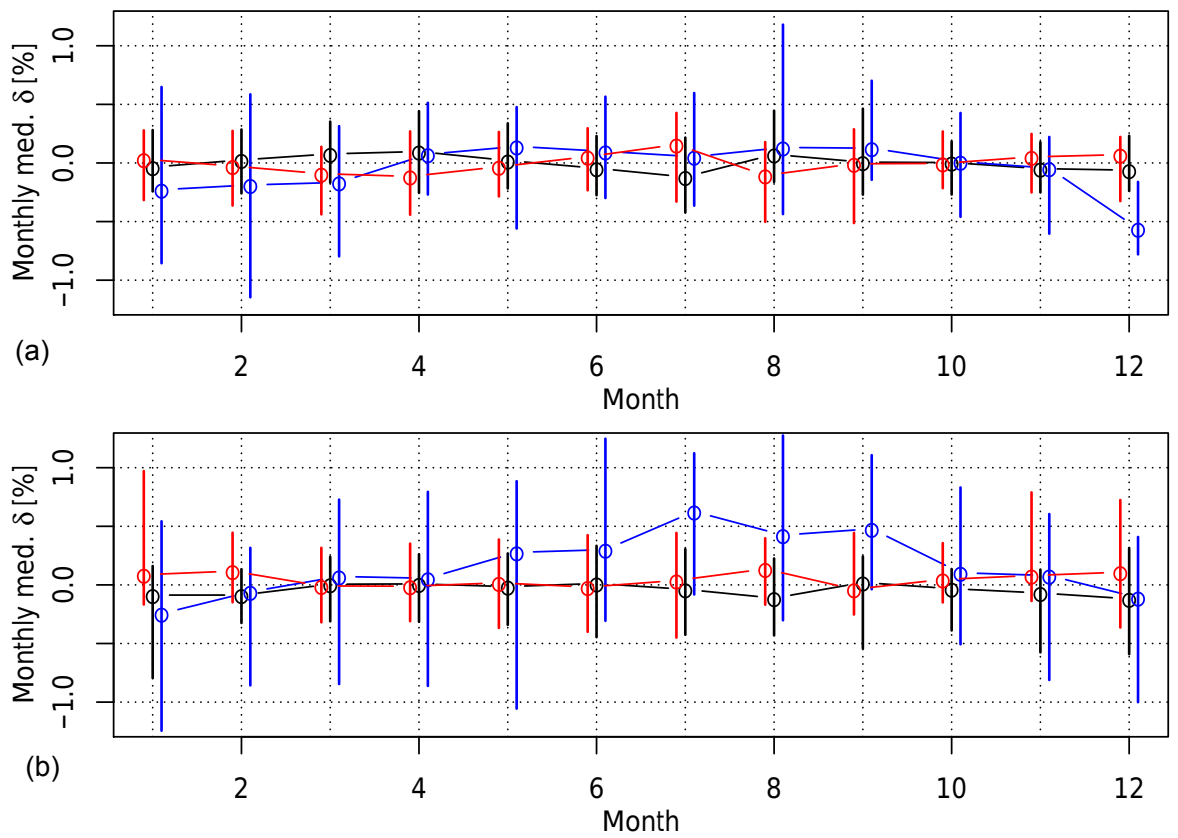

Figure 9. Seasonal cycle of the offset $\delta$ for Brewer $B_{040}, B_{072}$ and $B_{156}$ instruments in red, blue and green, respectively. Panel (a) corresponds to the Arosa period, while (b) corresponds to the Davos period. The bars correspond to the interquantiles $Q_{97.5 \%}-Q_{2.5 \%}$. 


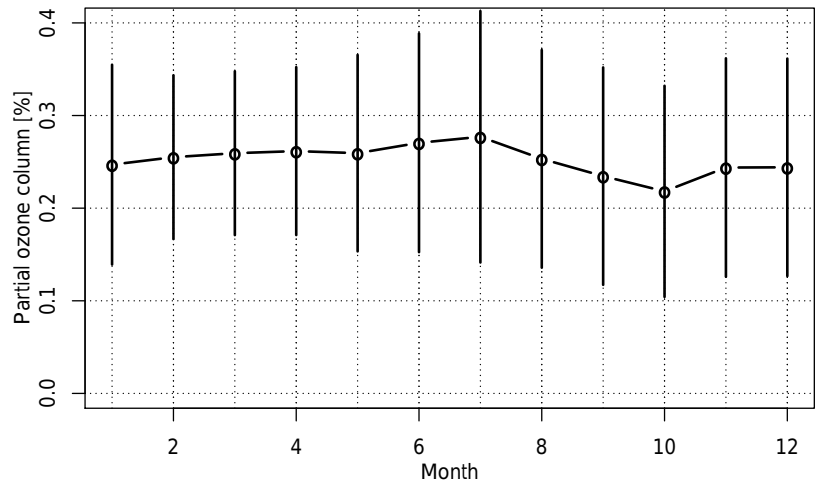

Figure 10. Monthly mean percentage contribution of the partial ozone column integrated from the Davos to Arosa altitudes based on the NABEL surface ozone measurements to the total column. The bars correspond to two SDs.

the short-term variability. The distribution of $\sigma_{B_{072}}$ is slightly larger than the other two, independently of the sites.

Regarding the $\delta$ parameter for the Arosa period, a larger $\delta_{B_{072}}$ distribution was expected, since it was not part of the reference built upon $B_{040}$ and $B_{156}$ instruments data. A factor $\sqrt{3}$ could be expected based on assumption that instrumental uncertainty are the same for all instruments and not correlated. For the Davos period, a shift $(\sim 0.2 \%)$ and a widening (factor $\sim 1.4$ ) of the $\delta_{B_{072}}$ distribution were observed.

Two additional factors were investigated that could potentially make a contribution to differences between measurements at the two investigated sites. First, the altitude difference created an additional partial column which is estimated of the order of $\sim 0.25 \%(\sim 0.8 \mathrm{DU})$ based on simple assumptions. This partial column is of the same order of magnitude as the median of the $\delta_{B_{072}}$ distribution for the Davos time period of $B_{072}$ instrument. Secondly, the upper panel of Fig. 9 shows a seasonal curvature in the $\delta_{B_{072}}$ distribution which had the signature of a stray-light problem. The investigation confirmed (see Fig. 8) a pronounced bias for Brewer $B_{072}$ for the winter months which could explain the mentioned curvature.

In summary, the present analysis did not show significant differences between coincident Brewer measurements at the two locations. The locations Davos and Arosa did not introduce discontinuities in the measurements of the ozone column measured by Brewer instruments. A small seasonal variation of the ozone column difference of $\pm \sim 0.2 \%$ was identified in the analysis which could not be distinguished from a stray-light bias of the test $B_{072}$ instrument. The altitude difference between the two sites generated a nonsignificant partial column based on surface ozone measurements embedded in the total uncertainties of the measurements.

Finally, the analysis of coincident data precluded the possibility of observing differences in the sampling of the daily cycle at the two sites, e.g., larger numbers of observations at low sun angles. The analysis of the horizons from Arosa and Davos sites was checked with the help of a high-resolution model of the topography. A bias of the ozone column due to a different sampling of the diurnal cycle caused by the topography of the sites was excluded.

The above conclusions are based on the analysis of Brewer instruments data, while the Arosa long-term record is based on Dobson measurements. Therefore the question of the validity of these results could be raised. The analysis of the agreement between the two types of instruments was the subject of the publication by Scarnato et al. (2009). It was shown that the time series of the differences between coincident data presented a seasonal cycle which was reduced by a correction based on the SC and taking into account the temperature of the ozone layer. Later on, Redondas et al. (2014) showed that these differences were further reduced by the introduction of the ozone cross section recently published by the University of Bremen (Gorshelev et al., 2014; Serdyuchenko et al., 2014). The agreement between the Arosa Brewer and Dobson data were shown to agree to $\leq 1 \%$ with no significant seasonal variation.

\section{Conclusions}

The motivation for this work was the perspective of a continuation of the Arosa total ozone column series at the Davos site. The analysis of the campaign data between the two stations separated horizontally by $13 \mathrm{~km}$ and vertically by $260 \mathrm{~m}$ showed that the two sites agree to better than $\sim 0.5 \%$, which represents the limit of the combined long-term stability and the precision of Brewer instruments. The monthly median differences are of the order of $\sim 0.2 \%$ and are superimposed with an additional seasonal cycle of the same order. None of these numbers are significant at the $95 \%$ confidence level. It remains speculative as to whether the altitude difference could be the reason for the small but nonsignificant difference on the ozone column. The quality of the Arosa data set and especially its continuity has always been a great concern in the maintenance and development of the LKO observatory. From this analysis, it can be concluded that the ozone column series initiated at Arosa in 1926 would not be disrupted by a change of site. Local factors potentially influencing the measurements are below the measurement variability and stay below the long-term stability of the Brewer instruments and within the uncertainties associated with the calibration procedures of the Brewer network. The introduction of the more recent laboratory-measured ozone cross sections in the processing of Brewer data as well as of the ozone layer effective temperature in the Dobson ozone column calculation ensure the safe transfer of the conclusions presented above to the Arosa long-term record based on Dobson instruments. The confirmation of these results with automated Dobson instruments is presently underway, and the results 
will be reported after completion of this second parallel measurement campaign.

Data availability. The data used for this analysis are available at the WOUDC for the Brewer $B_{040}$ instrument. The complete data sets can be requested by direct contact with the corresponding author. In the near future, they all will be available at the EUBREWNET data center (see European Cooperation in Science and Technology: COST ES 1207: A European Brewer Network (EUBREWNET), http://www.eubrewnet.org).

Author contributions. RS analyzed the data and wrote the first version of the manuscript. HS was in charge of the quality control and the preparation of the data sets. LE was responsible for the daily control of the Brewer $B_{072}$ in Davos. JK, LV, JG, LE and DR have revised the manuscript.

Competing interests. The authors declare that they have no conflict of interest.

Acknowledgement. The authors would like to thank Luka Modolo (MeteoSwiss) for the calculation of the horizon seen from the Arosa and Davos sites (Fig. 2).

Edited by: Mark Weber

Reviewed by: two anonymous referees

\section{References}

Basher, R. E.: Review of the Dobson spectrophotometer and its accuracy, WMO Global Ozone Research and Monitoring, Project, Report No. 13., Geneva, 1982.

Chevalier, A., Gheusi, F., Delmas, R., Ordóñez, C., Sarrat, C., Zbinden, R., Thouret, V., Athier, G., and Cousin, J.-M.: Influence of altitude on ozone levels and variability in the lower troposphere: a ground-based study for western Europe over the period 2001-2004, Atmos. Chem. Phys., 7, 4311-4326, https://doi.org/10.5194/acp-7-4311-2007, 2007.

Christodoulakis, J., Varotsos, C., Cracknell, A. P., Tzanis, C., and Neofytos, A.: An assessment of the stray light in 25 years of Dobson total ozone data at Athens, Greece, Atmos. Meas. Tech., 8, 3037-3046, https://doi.org/10.5194/amt-8-3037-2015, 2015.

Dobson, G. M. B.: Forty years' research on atmospheric ozone at Oxford: a history, Appl. Optics, 7, 387-405, 1968.

Dütsch, H. U.: An update of the Arosa ozone series to the present using a statistical instrument calibration, Q. J. Roy. Meteor. Soc., 110, 1079-1096, 1984.

Farman, J. C., Gardiner, B. G., and Shanklin, J. D.: Large losses of total ozone in Antarctica reveal seasonal $\mathrm{ClO}_{x} / \mathrm{NO}_{x}$ interaction, Nature, 315, 207-210, https://doi.org/10.1038/315207a0, 1985.

Fioletov, V. E., Kerr, J. B., McElroy, C. T., Wardle, D. I., Savastiouk, V., and Grajnar, T. S.: The
Brewer reference triad, Geophys. Res. Lett., 32, L20805, https://doi.org/10.1029/2005GL024244, 2005.

GCOS Climate Monitoring Principles: available at: http://www.wmo.int/pages/prog/gcos/Documents/GCOS_ Climate_Monitoring_Principles.pdf (last access: 5 November 2017), 2003.

Gorshelev, V., Serdyuchenko, A., Weber, M., Chehade, W., and Burrows, J. P.: High spectral resolution ozone absorption crosssections - Part 1: Measurements, data analysis and comparison with previous measurements around $293 \mathrm{~K}$, Atmos. Meas. Tech., 7, 609-624, https://doi.org/10.5194/amt-7-609-2014, 2014.

Karppinen, T., Redondas, A., Garc ̃̃-a, R. D., Lakkala, K., McElroy, C. T., and Kyrö, E.: Compensating for the effects of stray light in single-monochromator Brewer spectrophotometer ozone retrieval, Atmos. Ocean, 53, 66-73, https://doi.org/10.1080/07055900.2013.871499, 2015.

Kerr, J. B. and McElroy, C. T.: Total ozone measurements made with the Brewer ozone spectrophotometer during STOIC, J. Geophys. Res., 100, 9225-9230, https://doi.org/10.1029/94JD02147, 1995.

Kerr, J. B., McElroy, C. T., and Olafson, R. A.: Measurements of total ozone with the Brewer spectrophotometer, in: Proc. of the Quadr. Ozone Symp., edited by: London, J., Natl. Cent. for Atmos. Res., Boulder CO, 74-79, 1981.

Kerr, J. B., McElroy, C. T., and Wardle, D. I.: The Brewer instrument calibration center 1984-1996, in: Proc. of the XVIII Quadr. Ozone Symp., L'Aquila, edited by: Bojkov, R. D., and Visconti, G., L'Aquila, Italy, 12-21 September 1996, Publication supported by Parco Scientifico e Tecnologico d'Abruzzo, 915918, 1998.

Komyhr, W. D.: Operations handbook - ozone observations with a Dobson spectrophotometer, Global Ozone Research and Monitoring, Project Report 6, WMO, Geneva, Switzerland, 1980.

Komhyr, W. D., Grass, R. D., and Leonard, R. K.: Dobson spectrophotometer 83: a standard for total ozone measurements, 1962-1987, J. Geophys. Res., 94, 9847-9861, 1989.

Pawson, S. and Steinbrecht, W., Charlton-Perez, A. J., Fujiwara, M., Karpechko, A.Yu., Petropavlovskikh, I., Urban, J., and Weber, M.: Update on global ozone: past, present, and future, Scientific Assessment of Ozone Depletion: 2014, Chapter 2, Global Ozone Research and Monitoring Project - Report No. 55, World Meteorological Organization, Geneva, Switzerland, 2014.

Petropavlovskikh, I., Evans, R., McConville, G., Miyagawa, K., and Oltmans, S.: Effect of the out-of-band stray light on the retrieval of the Umkehr Dobson ozone profiles, Int. J. Remote Sens., 30, 6461-6482, https://doi.org/10.1080/01431160902865806, 2009.

Petropavlovskikh, I., Evans, R., McConville, G., Oltmans, S., Quincy, D., Lantz, K., Disterhoft, P., Stanek, M., and Flynn, L.: Sensitivity of Dobson and Brewer Umkehr ozone profile retrievals to ozone cross-sections and stray light effects, Atmos. Meas. Tech., 4, 1841-1853, https://doi.org/10.5194/amt-4-18412011, 2011.

Redondas, A. and Rodriquez-Franco, J.: Ninth Intercomparison Campaign of the Regional Brewer Calibration Center Europe (RBCC-E), WMO GAW Report No. 224, WMO, Geneva, December, 2015.

Redondas, A., Evans, R., Stuebi, R., Köhler, U., and Weber, M.: Evaluation of the use of five laboratory-determined ozone absorption cross sections in Brewer and Dobson re- 
trieval algorithms, Atmos. Chem. Phys., 14, 1635-1648, https://doi.org/10.5194/acp-14-1635-2014, 2014.

Redondas, A., Rodriquez-Franco, J., Gröbner, J., Köhler, U., and Stübi, R.: Seventh Intercomparison Campaign of the Regional Brewer Calibration Center Europe (RBCC-E), WMO GAW Report No. 216, WMO, Geneva, March, 2015.

Scarnato, B., Staehelin, J., Peter, T., Gröbner, J., and Stübi, R.: Temperature and slant path effects in Dobson and Brewer total ozone measurements, J. Geophys. Res.-Atmos., 114, D24303, https://doi.org/10.1029/2009JD012349, 2009.

Scarnato, B., Staehelin, J., Stübi, R., and Schill, H.: Long-term total ozone observations at Arosa (Switzerland) with Dobson and Brewer instruments (1988-2007), J. Geophys. Res.-Atmos., 115, D13306, https://doi.org/10.1029/2009JD011908, 2010.

Serdyuchenko, A., Gorshelev, V., Weber, M., Chehade, W., and Burrows, J. P.: High spectral resolution ozone absorption crosssections - Part 2: Temperature dependence, Atmos. Meas. Tech., 7, 625-636, https://doi.org/10.5194/amt-7-625-2014, 2014.
Solomon, S.: Stratospheric ozone depletion: a review of concepts and history, Rev. Geophys., 37, 275-316, 1999.

Staehelin, J., Renaud, A., Bader, J., McPeters, R., Viatte, P., Hoegger, B., Bugnion, V., Giroud, M., and Schill, H.: Total ozone series at Arosa (Switzerland): homogenization and data comparison, J. Geophys. Res., 103, 5827-5842, https://doi.org/10.1029/97JD02402, 1998.

Staehelin, J., Brönnimann, S., Peter, T., Stübi, R., Viatte, P., and Tummon, F.: The value of Swiss long-term ozone observations for international atmospheric and research, in: From Weather Observations to Atmospheric and Climate Sciences in Switzerland - Celebrating 100 Years of the Swiss Society for Meteorology, edited by: Willemse, S. and Furger, M., vdf Hochschulverlag AG an der ETH Zürich, Zürich, 325-349, 2016.

Stübi, R., Schill, H., Klausen, J., Vuilleumier, L., and Ruffieux, D.: Reproducibility of total ozone column monitoring by the Arosa Brewer spectrophotometer triad, J. Geophys. Res.-Atmos., 122, 4735-4745, https://doi.org/10.1002/2016JD025735, 2017. 